\title{
Techniques for reducing false alarms in infrared forest-fire automatic detection systems
}

\author{
A. Ollero*, B.C. Arrue, J.R. Martinez, J.J. Murillo \\ Departamento de Ingeniería de Sistemas y Automática, Escuela Superior de Ingenieros. Universidad de Sevilla, \\ Camino de los Descubrimientos s/n, 41092 Sevilla, Spain
}

Received 5 December 1997; accepted 20 August 1998

\begin{abstract}
This paper presents techniques to reduce false alarms in forest-fire detection systems based on infrared cameras. Several software components to implement these techniques are discussed. The components are based on thresholds, oscillation detection, matching of visual and infrared images, memory, meteorological information, motion, size, shape, solar conditions and location. The paper includes a description of experiments in two forest environments, showing the ability of the proposed techniques to discriminate between forest fires and false alarms. (C) 1999 Elsevier Science Ltd. All rights reserved.
\end{abstract}

Keywords: Image processing; pattern recognition; infrared detectors; environmental engineering; telemetry

\section{Introduction}

Wildfire detection and monitoring is required to minimize damage to forest, wilderness and agricultural areas, and hazard to people. In particular, forest surveillance and early forest-fire detection have significant relevance. These activities have been traditionally carried out by means of lookouts in the affected areas. Experienced people in watchtowers is the most extensively used method. Surveying from an aircraft has also been done in critical seasons with high risks for wild fires.

However, the high cost and the subjectivity of human surveillance play an important role. Notice that in some regions, such as the countries of southern Europe, long periods of high forest-fire risks exist. Thus, the development of sensor technologies and automatic surveillance and detection systems is an important research and development topic.

It should be noted that several sensor technologies have already been applied in forest-fire detection. Thus, satellite-based techniques using meteorological satellites

\footnotetext{
*Corresponding author. Tel.: +3495448 7349; fax: +3495448 7340; e-mail: aollero@cartuja.us.es
}

have been proposed to collect real-time information. Detection is based on the use of NOAA AVHRR images (Illera et al., 1995). These techniques are valuable in large and homogeneous regions. However, in many areas, the detection period and the resolution provided by these systems is not yet adequate for early fire detection.

Early wildfire-detection techniques using smoke plume identification have also been presented (Vries and Kemp, 1994). The principle is based on detection against a background of vegetation or sky. The basic method of detecting a smoke plume at the beginning of a wildfire is based on a comparison of subsequent images. In particular, a sensor using three cameras, each employing a linear charge couple photo diode detector array (CCPD), has been developed. The detector process relies on the detection of color differences rather than differences in light intensity. Thus, varying natural background illumination does not generate false alarms.

This paper deals with infrared detection systems in the framework of the project 'distributed environmental disaster information and control systems (DEDICS)' funded by the European Commission (DG XIII) in the telematics application program (environment area). DEDICS is being designed to be adapted to a wide range of disasters (Wybo and Jaber, 1996). However, its first application is concerned with forest fires, which constitute 


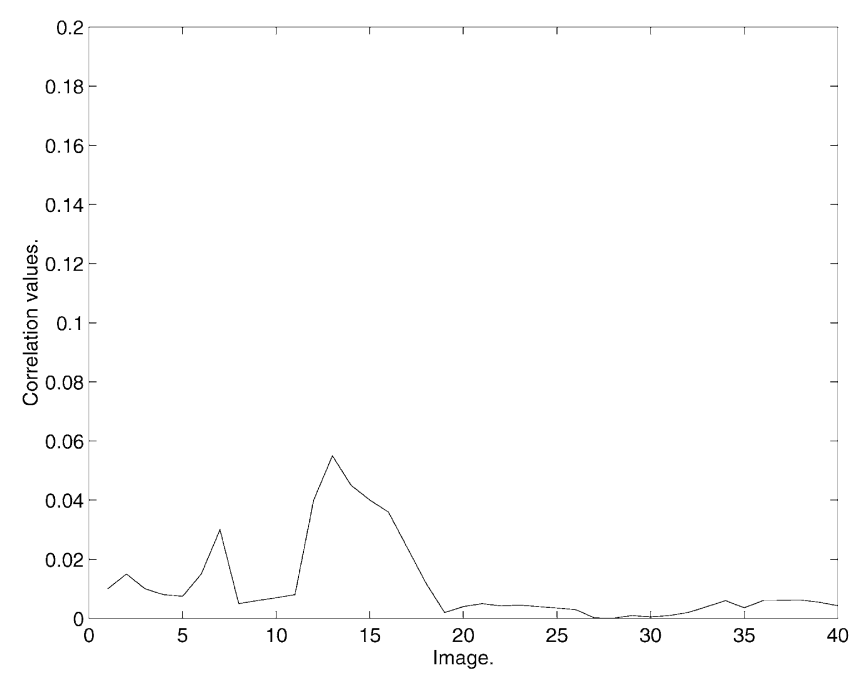

Fig. 13. Result of a correlation technique for the solar reflection in experiment 3.

to their origins: heated objects, solar reflections, artificial lights and combustion sources due to human activities.

Some detection software components have been proposed. These components are based on thresholds, oscillation detection, matching of visual/infrared images, memory, meteorological information, motion, size, shape, solar conditions and location.

The analysis of infrared images can be used to discriminate fires from solar reflections. Heated objects are characterized by their low average brightness level, so they can be identified using appropriate dynamic thresholds. Solar reflections are characterized by having considerable stability in the value of the pixels. They can be distinguished from fires by the use of oscillation-detection techniques. Combustion sources due to human activities, and artificial lights, can be detected by the use of infrared/visual matching methods and topographic and fuel maps.

The false alarm reduction system has been implemented on a Pentium $120 \mathrm{MHz}$ PC with a Mutech MV1000 digitizer card.

The total time required for the application of the false-alarm reduction components is lower than $15 \mathrm{~s}$. In many cases, only a few components are needed, and this time is greatly reduced. Furthermore, this time is not relevant when considering the detection cycle (time to cover the whole surveyed area using the positioning system) in the observatories, which is about $4 \mathrm{~min}$.

Further work will include its integration within the full DEDICS system, and a demonstration of this Telematic system in daily operation.

\section{Acknowledgements}

Partially funded by the European Commission (DG XIII, Telematics for Environment), the DEDICS project has been undertaken by eleven partners, from six European countries: Ecole des Mines de Paris (France, coordinator), Algosystems (Greece), Fisia-Teletron (Italy), IBP-Pietzsch (Germany), AICIA-Universidad de Sevilla (Spain), FABA-BAZAN (Spain), OANAK (Greece), University of Turing (Italy), Technical University of Athens (Greece), Athens University of Economics and Business (Greece) and University of Coimbra (Portugal).

The authors acknowledge the collaboration of A. Criado and A. Cardona from FABA-BAZAN, for their information about the Bosque system and False Alarm Requirements, to Francisco Rodriguez y Silva and Francisco Salas of the Dirección General de Gestión del Medio Natural (Junta de Andalucía) for the information and support provided for the experiments, and to Javier Luengo (Dirección General de la Conservación de la Naturaleza) for his valuable comments.

The authors thankfully acknowledge the valuable collaboration of Emilio Salgueiro who played a very important role at the beginning of the DEDICS projects and who died in a traffic accident in 1996.

\section{References}

Carrega, P. (1990). Climatology and index of forest fire hazard in mediterranean France. Proc., Int. Conf. on Forest Fire Research. Coimbra.

Gandia, A., Criado, A., \& Rallo, M. (1994). El sistema BOSQUE, alta tecnologia en defensa del medio ambiente. DYNA, no. 6, pp. 34-38.

Hudson, R. D. (1969). Infrared system engineering. Wiley, New York.

Illera, P., Fernández, A., \& Casanova, J. L. (1995). Automatic algorithm for the detection and analysis of fires by means of NOAA AVHRR images. Earsel advances in remote sensing. (Vol 4 No. 3-XII).

Laurenti, A., \& Neri, A. (1996). Remote sensing, communications and information technologies for vegetation fire emergencies. Proc. TIEMEC'96, Montreal.

Lim Jae, S. (1990). Two-dimensional signal and image processing. Prentice Hall Signal Processing Series, Prentice-Hall, Englewood Cliffs, NJ.

Murillo, J. J., Ollero, A., Arrúe, B.C., \& Martínez, J. R. (1997). A hybrid infrared/visual system for improving reliability of fire detection systems. IF AC Symp. on Fault Detection, Supervision and Safety for Technical Processes: SAFEPROCESS'97. Kingston Upon Hull, UK.

Thornthwaite, C.W., \& Mather, J.R. (1955). The water balance. Climatology, 8(1), 104.

Vries, J.S., \& Kemp, R.A.W. (1994). Results with a multi-spectral autonomous wildfire detection system. Proc. 2nd Conf. Forest Fire Research (Vol. II, pp. 779-791) C.P. 27, Coimbra, November 1994.

Wybo, J.L., \& Jaber, A. (1996). DEDICS: a distributed environmental disaster information and control system. Proc. TIEMEC'96, Montreal. 